\title{
A humanização na educação médica no Brasil
}

\author{
Humanization in medical education in Brazil \\ Humanización en la educación médica en Brasil
}

\section{Resumo}

Introdução: a formação do profissional médico vem passando por mudanças, entre as quais a humanização ganha destaque. Objetivo: compreender como a humanização na educação médica vem sendo abordada na literatura científica brasileira, buscando analisar as características dos estudos publicados, conhecer quais os conceitos atribuídos ao termo humanização e identificar as estratégias pedagógicas favoráveis ao desenvolvimento da humanização. Metodologia: estudo exploratório-descritivo, consistindo em revisão integrativa de literatura. A busca dos estudos ocorreu em 2018, na Biblioteca Virtual em Saúde, utilizando cruzamentos dos descritores: educação, educação médica, estudantes de medicina, humanização e humanização da assistência. Após os cruzamentos, os artigos foram salvos em pastas, nomeados de 01 a 145. Realizou-se a leitura dos títulos e resumos, aplicando critérios de inclusão e exclusão, ficando 53 artigos para leitura completa, dos quais foram selecionados 42 estudos por se adequarem aos objetivos da pesquisa. Resultados: dos estudos analisados, 27 apresentaram um conceito de humanização relacionado à escuta, empatia, vínculo, ambiência e comunicação, evidenciando relação com o conceito assumido pela Política Nacional de Humanização. Outros 15 estudos relacionaram a humanização com a integralidade, se referindo a diversos conhecimentos, trabalho em equipe, cultura, visão social e emocional. Também, 22 estudos referiram humanização como garantia de direitos, abrangendo a ética e a responsabilidade social. Conclusão: conclui-se que a humanização é um termo tratado de forma polissêmica na literatura científica e que diferentes estratégias pedagógicas têm sido utilizadas com o propósito de promover a humanização na educação médica brasileira.

Palavras chave: Educação; Estudantes de medicina; Humanização da assistência.

\begin{abstract}
Introduction: the training of medical professionals has been undergoing changes, among which humanization is highlighted. Objective: to understand how humanization in medical education has been addressed in the Brazilian scientific literature, seeking to analyze the characteristics of published studies, discovering the concepts attributed to the term humanization and identifying pedagogical strategies that favor the development of humanization. Methodology: exploratory-descriptive study, consisting of an integrative literature review. The search for studies took place in 2018 , in the Virtual Health Library, using intersections of descriptors: education, medical education, medical students, humanization and humanization of care. After the crossings, the articles were saved in folders, named from 01 to 145. The titles and abstracts were read, applying inclusion and exclusion criteria, leaving 53 articles for full reading, of which 42 studies were selected as they were suitable. to the research objectives. Results: from the analyzed studies, 27 presented a concept of humanization related to listening, empathy, bonding, ambience and communication, showing a relationship with the concept assumed by the National Humanization Policy. Another 15 studies related humanization
\end{abstract}


with integrality, referring to different knowledge, teamwork, culture, social and emotional vision. Also, 22 studies mentioned humanization as a guarantee of rights, covering ethics and social responsibility. Conclusion: it is concluded that humanization is a term treated in a polysemic way in the scientific literature and that different pedagogical strategies have been used with the purpose of promoting humanization in Brazilian medical education.

Keywords: Education; Medical students; Humanization of assistance.

\section{Resumen}

Introducción: la formación de los profesionales médicos ha ido experimentando cambios, entre los que se destaca la humanización. Objetivo: comprender cómo se ha abordado la humanización en la educación médica en la literatura científica brasileña, buscando analizar las características de los estudios publicados, descubriendo los conceptos atribuidos al término humanización e identificando estrategias pedagógicas que favorezcan el desarrollo de la humanización. Metodología: estudio exploratorio-descriptivo, consistente en una revisión integradora de la literatura. La búsqueda de estudios se realizó en 2018, en la Biblioteca Virtual en Salud, utilizando intersecciones de descriptores: educación, educación médica, estudiantes de medicina, humanización y humanización de la atención. Tras los cruces, los artículos se guardaron en carpetas, nombradas del 01 al 145. Se leyeron los títulos y resúmenes aplicando criterios de inclusión y exclusión, quedando 53 artículos para lectura completa, de los cuales se seleccionaron 42 estudios por conveniencia. investigar objetivos. Resultados: de los estudios analizados, 27 presentaron un concepto de humanización relacionado con la escucha, la empatía, el vínculo, el ambiente y la comunicación, mostrando una relación con el concepto asumido por la Política Nacional de Humanización. Otros 15 estudios relacionaron la humanización con la integralidad, refiriéndose a diferentes saberes, trabajo en equipo, cultura, visión social y emocional. Asimismo, 22 estudios mencionaron la humanización como garantía de derechos, abarcando la ética y la responsabilidad social. Conclusión: se concluye que humanización es un término tratado de manera polisémica en la literatura científica y que se han utilizado diferentes estrategias pedagógicas con el propósito de promover la humanización en la educación médica brasileña.

Palabras clave: Educación; Estudiantes de medicina; Humanización de la asistencia.

\section{Introdução}

A expressão educação médica refere-se ao processo de formação do profissional médico, incluindo os níveis de graduação, pós-graduação e educação continuada segundo DeCS (2017). Ao longo do tempo, essa formação vem passando por mudanças significativas, nas quais o tema da humanização tem se feito presente, com vistas a promover uma compreensão holística do ser humano. O ato de humanizar, no âmbito da educação médica, se consolida ao colocar em cena valores morais, que agreguem ao estudante princípios baseados na cidadania funcional pluricultural, na integralidade e nos direitos do ser humano segundo Brasil (2014) e Zeni (2011)

A perspectiva humanista propõe que o paciente deve ser visto como um ser único, embora complexo, que requer respeito, acolhimento e empatia. Ademais, pressupõe o desenvolvimento de habilidades que permitam ao profissional ajudar em momentos de sofrimento. Assim, a educação médica, ao se basear nos princípios da humanização, enfrenta alguns desafios, sendo o principal o de formar médicos preparados para realizar um cuidado adequado ao paciente conforme Casate (2012) e Zeni (2011). Vale ressaltar que, no Brasil, o conceito de humanização está voltado para a valorização dos usuários, trabalhadores e gestores da saúde, promovendo autonomia e ampliando a capacidade de os pacientes transformarem a sua realidade, por meio da criação de vínculos solidários e da participação coletiva nos processos de gestão e produção da saúde segundo Brasil (2004) Porém, tem sido referido que a humanização é tratada como um conceito polissêmico na literatura científica brasileira, permeado por imprecisões, comportando diversos enunciados relativos a distintas práticas de gestão e modelos de atenção, não necessariamente colocando o foco na valorização dos usuários no processo de produção da saúde segundo Braz (2013).

A partir da criação do Sistema Único de Saúde (SUS), a humanização ganhou relevância no ensino de graduação, passando a se preconizar a incorporação de conteúdos humanistas e a adoção de práticas com base pedagógica humanizada. Contudo, foram as Diretrizes Curriculares Nacionais (DCNs) do curso de Graduação em Medicina, instituídas em 2001 e atualizadas em 2014, que deram sentido à maior mudança do ensino na formação profissional. Elas objetivam contemplar as necessidades de toda a população, com maior interação entre profissionais e usuários, com base em escuta qualificada, olhar 
abrangente ao outro, acolhimento e compromisso entre todos os envolvidos no cotidiano das práticas de saúde conforme Brasil (2014) Zeni (2011) e Brasil (2001).

Nesse contexto, a Política Nacional de Humanização (PNH) surge com o intuito de contribuir para a qualificação da atenção e da gestão do SUS. Assim, a humanização, em decorrência da PNH, busca mudanças na cultura assistencial e na gestão. Então, depende se de alterações nos processos de trabalho, na dinâmica do convívio em equipe, nos métodos de planejamento, decisão e cooperação para que ocorram as modificações nos modos de atendimento em saúde segundo Binz (2008) Brasil (2004).

Assim, é importante salientar que o desenvolvimento de habilidades para a humanização precisa ser promovido durante todo o processo de formação, iniciando desde a graduação, tanto no nível teórico quanto no das vivências nos cenários de práticas segundo Zeni (2011). Dito de outra forma, a humanização é questão que deveria permear a graduação e ganhar continuidade, na perspectiva de um processo permanente, mesmo após a inserção do profissional no mercado de trabalho, segundo Silva (2011). Porém, na realidade da educação médica, ainda são observados vínculos superficiais entre professores, alunos e usuários, com fragilidades de acolhimento e de respeito àqueles que deveriam ser o foco das práticas de atenção à saúde conforme Binz (2010). Diante do exposto, considera-se que a humanização é questão desafiadora e requer uma visão que inclua a complexidade de fatores implicados com o tema de acordo com Casate (2012). A partir disso, na perspectiva de ampliar o debate e fortalecer o enfrentamento dos desafios que acometem a perspectiva da humanização nos processos de educação médica, este estudo opera com a seguinte problemática: como a humanização na educação médica vem sendo abordada na literatura científica brasileira? Nesse sentido, este estudo teve por objetivo geral compreender como a humanização na educação médica vem sendo abordada na literatura científica brasileira, buscando a) analisar as características dos estudos publicados sobre o assunto, b) conhecer os conceitos atribuídos ao termo humanização na educação médica e c) identificar as estratégias pedagógicas que têm sido referidas como favoráveis ao desenvolvimento da humanização nos processos de formação profissional.

\section{Metodologia}

Trata-se de estudo com delineamento exploratório-descritivo, contendo estudos de 1991 a 2018, desenvolvido por meio de uma revisão integrativa de literatura, metodologia que permitiu incluir literatura teórica e empírica, bem como estudos com diferentes abordagens. Os estudos incluídos foram analisados de forma sistemática, permitindo que o leitor acessasse uma síntese do conhecimento existente sobre o tema estudado. Para tanto, elaborou-se um protocolo com a descrição das etapas do processo de revisão: a) identificação do tema e formulação da pergunta e dos objetivos de pesquisa; b) estabelecimento de critérios de exclusão e inclusão; c) seleção dos estudos; d) definição das informações a serem extraídas dos estudos selecionados e construção de matriz de pesquisa; e) análise e discussão dos resultados conforme Ganong (1987). O protocolo utilizado foi validado por pesquisador com experiência no tema e na metodologia de estudo.

Em virtude da quantidade crescente e da complexidade de informações na área da saúde, tornou-se imprescindível o desenvolvimento de artifícios, no contexto da pesquisa cientificamente embasada, capazes de delimitar etapas metodológicas mais concisas e de propiciar, aos profissionais, melhor utilização das evidências elucidadas em inúmeros estudos. Nesse cenário, a revisão integrativa emerge como uma metodologia que proporciona a síntese do conhecimento e a incorporação da aplicabilidade de resultados de estudos significativos na prática conforme Silveira (2005).

A busca dos estudos ocorreu no dia 30 de agosto de 2018, sendo realizada nas bases de dados da Biblioteca Virtual em Saúde (BVS), com os seguintes descritores: —Educaçãoll, —Educação Médicall, —Estudantes de Medicinall, -Humanizaçãoll e -Humanização da Assistênciall, conforme cruzamentos detalhados na Tabela 1. Em cada cruzamento foram aplicados os seguintes filtros, sequencialmente: Idioma (Português), Tipo de documento (Artigo) e, por último, texto completo. 
Tabela 1. Síntese do percurso de busca e seleção dos estudos para a revisão integrativa de literatura sobre Humanização na Educação Médica no Brasil, 2018.

\begin{tabular}{|c|c|}
\hline CRUZAMENTOS DOS DESCRITORES & TOTAL DE ESTUDOS \\
\hline —Humanizaçãoll and —Educação\| and —Estudantes de medicinall & 25 \\
\hline —Humanizaçãoll and —Educação médicall & 69 \\
\hline —Humanização da assistênciall and —Educação médicall & 39 \\
\hline —Humanização da assistênciall and —Educação\| and —Estudantes de medicinall & 12 \\
\hline Total de estudos resultantes da busca & 145 \\
\hline Estudos Duplicados & 77 \\
\hline Total de Estudos Pré-selecionados pela leitura dos títulos e resumos & 68 \\
\hline Estudos que não tinham relação com o tema da revisão & 15 \\
\hline Estudos que não correspondiam aos objetivos da revisão & 11 \\
\hline Total de estudos selecionados & 42 \\
\hline
\end{tabular}

Fonte: Elaboração dos autores (2021).

Para a seleção dos estudos, foram adotados critérios de inclusão: ter formato de artigo científico, publicado em português, disponível online em texto completo de acesso livre, ter objetivo relacionado ao objeto deste estudo é tratar do tema no contexto brasileiro. Os critérios de exclusão adotados foram: artigos do tipo revisões bibliográficas não metodologicamente sistematizadas, cartas, resenhas, editoriais, teses e dissertações; publicações do tipo: livros, capítulos de livros, publicações governamentais, boletins informativos, monografias ou trabalhos de conclusão de curso e estudos duplicados. Após os cruzamentos, os artigos foram salvos em pastas específicas, nomeadas conforme cruzamentos e numerados de 01 a 145.

Após a leitura dos títulos e resumos, contataram-se 77 estudos duplicados, os quais foram excluídos. Considerando a relação entre os propósitos dos estudos e o objeto desta revisão, 15 artigos foram excluídos, pois apresentavam distanciamento do tema, restando 53 estudos para serem lidos na íntegra. A partir desta leitura, foram excluídos outros 11 artigos, que não corresponderam aos objetivos dessa pesquisa. Dessa forma, foram selecionados 42 estudos para compor esta revisão, dos quais foram extraídas as informações que alimentaram uma matriz analítica composta pelos seguintes itens: código de identificação, ano de publicação, tipo de documento, periódico, autores, título, objetivo do estudo, tipo de estudo, abordagem metodológica, cenário de pesquisa, principais resultados e conclusões. A Tabela 1 apresenta o caminho percorrido na busca e seleção dos estudos para composição dessa revisão.

A análise dos dados coletados dos artigos selecionados foi realizada de forma descritiva, a fim de sumarizar as características dos estudos brasileiros publicados sobre o tema em estudo ao longo dos anos. Da mesma forma, os conceitos de humanização adotados nos artigos selecionados foram compilados e, posteriormente, analisados em termos de suas convergências, divergências e diversidade. Finalmente, foram identificadas e categorizadas as estratégias pedagógicas utilizadas para o desenvolvimento da humanização na educação médica. As ideias agruparam-se por similaridade, buscando-se, também, identificar divergências importantes apontadas pelos artigos selecionados, assim como possíveis lacunas de conhecimento. Esse processo de análise foi desenvolvido de modo a se construir uma síntese narrativa, a partir das seguintes categorias e subcategorias: 1) Conceito atribuído ao termo humanização na educação médica - a) Conceitos relacionados à PNH, b) 
Humanização como integralidade, c) Humanização como possibilidades de garantir direitos aos usuários; 2) Estratégias pedagógicas utilizadas pelos cursos de graduação em medicina - a) Estratégias pedagógicas extramuros; b) Estratégias pedagógicas intramuros.

\section{Resultados e Discussão}

\subsection{Perfil da produção científica brasileira sobre humanização na educação médica}

Os 42 artigos selecionados para a revisão integrativa de literatura são apresentados a seguir (Tabela 2), conforme o ano e periódico de publicação, autores e título, a fím de caracterizar o perfil dos estudos. Uma análise temporal das publicações selecionadas para o estudo (Figura 1), por década, indicou que a temática vem provocando interesse crescente na comunidade científica ao longo dos anos. Já quanto ao veículo de divulgação científica, identificou-se que 32 (76,2\%) dos artigos selecionados foram publicados em periódicos da área da Medicina, tendo destaque a Revista Brasileira de Educação Médica - que publicou $26(81,25 \%)$ destes estudos - e 10 (23,8\%) foram publicados em periódicos de outras áreas, como Saúde Pública e Coletiva, Enfermagem, Educação e Trabalho na Saúde e Bioética. Isso demonstra que a humanização, sob a perspectiva da educação médica, vem sensibilizando a classe médica, que tem buscado refletir e discutir sobre esse tema, mantendo-o em evidência.

Tabela 2. Estudos selecionados para a revisão integrativa de literatura sobre Humanização na Educação Médica no Brasil, 2018.

\begin{tabular}{|c|c|c|c|c|}
\hline $\mathbf{A}^{\mathrm{a}}$ & $\mathbf{A N O}^{\mathrm{b}}$ & PERIÓDICO & AUTORES & TÍTULO \\
\hline 1 & 1993 & $\begin{array}{l}\text { Cadernos de Saúde } \\
\text { Pública }\end{array}$ & HOFFMANN, Leandro. & $\begin{array}{l}\text { A Morte na infância e sua representação para o } \\
\text { médico - reflexões sobre a prática pediátrica } \\
\text { em diferentes contextos }\end{array}$ \\
\hline 2 & 2004 & $\begin{array}{l}\text { Revista Associação } \\
\text { Médica do RS }\end{array}$ & $\begin{array}{l}\text { QUINTANA, Alberto Manuel } \\
\text { et al. }\end{array}$ & Humanização e estresse na formação médica \\
\hline 3 & 2005 & $\begin{array}{l}\text { Ciência \& Saúde } \\
\text { Coletiva }\end{array}$ & $\begin{array}{l}\text { HOTIMSMY, Sonia N.; } \\
\text { SCHRAIBER, Lilia Blima. }\end{array}$ & $\begin{array}{l}\text { Humanização no contexto da formação em } \\
\text { obstetrícia }\end{array}$ \\
\hline 4 & 2008 & $\begin{array}{l}\text { Revista Brasileira de } \\
\text { Educação Médica }\end{array}$ & RIOS, Izabel Cristina et al. & $\begin{array}{l}\text { A Integração das disciplinas de humanidades } \\
\text { médicas na faculdade de medicina da USP - um } \\
\text { caminho para o ensino }\end{array}$ \\
\hline 5 & 2008 & $\begin{array}{l}\text { Revista Brasileira de } \\
\text { Educação Médica }\end{array}$ & $\begin{array}{l}\text { GIL, Célia Regina Rodrigues } \\
\text { et al. }\end{array}$ & $\begin{array}{l}\text { Interação ensino, serviços e comunidade: } \\
\text { desafios e perspectivas de uma experiência de } \\
\text { ensino-aprendizagem na atenção básica }\end{array}$ \\
\hline 6 & 2008 & $\begin{array}{l}\text { Revista Brasileira de } \\
\text { Educação Médica }\end{array}$ & $\begin{array}{l}\text { PEROSA, Gimol B.; } \\
\text { RANZANI, Priscula M. }\end{array}$ & $\begin{array}{c}\text { Capacitação do médico para comunicar más } \\
\text { notícias à criança }\end{array}$ \\
\hline 7 & 2008 & $\begin{array}{l}\text { Revista Brasileira de } \\
\text { Educação Médica }\end{array}$ & $\begin{array}{l}\text { CAMPOS, Maria Angélica de } \\
\text { Figueiredo; FORSTER, } \\
\text { Aldaísa Cassanho. }\end{array}$ & $\begin{array}{l}\text { Percepção e avaliação dos alunos do } \\
\text { curso de medicina de uma escola médica } \\
\text { pública sobre a importância do estágio em } \\
\text { saúde da família na sua formação }\end{array}$ \\
\hline 8 & 2009 & $\begin{array}{l}\text { Revista Brasileira de } \\
\text { Educação Médica }\end{array}$ & $\begin{array}{l}\text { PEREIRA, Ana M. T. B.; } \\
\text { GONÇALVES, Maria B. }\end{array}$ & $\begin{array}{l}\text { Transtornos emocionais e a formação em } \\
\text { medicina: um estudo longitudinal }\end{array}$ \\
\hline 9 & 2009 & $\begin{array}{l}\text { Revista Brasileira de } \\
\text { Educação Médica }\end{array}$ & $\begin{array}{l}\text { ALVES, Antonia Núbia de } \\
\text { Oliveira } \text { et al. }\end{array}$ & $\begin{array}{l}\text { A Humanização e a formação médica na } \\
\text { perspectiva dos estudantes de medicina da } \\
\text { UFRN - Natal - RN - Brasil }\end{array}$ \\
\hline
\end{tabular}




\begin{tabular}{|c|c|c|c|c|}
\hline 10 & 2009 & $\begin{array}{l}\text { Revista Brasileira de } \\
\text { Educação Médica }\end{array}$ & $\begin{array}{l}\text { AZEVEDO, Cristina C.; } \\
\text { RIBEIRO, Maria A. T.; } \\
\text { BATISTA, S. H. S. Silva. }\end{array}$ & $\begin{array}{c}\text { O Humanismo na perspectiva de estudantes de } \\
\text { Medicina da UFAL }\end{array}$ \\
\hline 11 & 2009 & $\begin{array}{l}\text { Revista Brasileira de } \\
\text { Medicina da Família e } \\
\text { Comunidade }\end{array}$ & $\begin{array}{l}\text { LANDSBERG, Gustavo de } \\
\text { Araújo Porto. }\end{array}$ & $\begin{array}{l}\text { Vendo o outro através da tela: cinema, } \\
\text { humanização da educação médica e medicina } \\
\text { de família e comunidade }\end{array}$ \\
\hline 12 & 2009 & $\begin{array}{l}\text { Revista Brasileira de } \\
\text { Educação Médica }\end{array}$ & $\begin{array}{c}\text { ARAGÃO, Julio Cesar Soares } \\
\text { et al. }\end{array}$ & $\begin{array}{c}\text { O Uso da técnica de role-playing como } \\
\text { sensibilização dos alunos de medicina para o } \\
\text { exame ginecológico }\end{array}$ \\
\hline 13 & 2009 & Acta Bioethica & $\begin{array}{l}\text { NOVAES, Maria Rita } \\
\text { Carvalho Garbi et al. }\end{array}$ & $\begin{array}{c}\text { Inserção dos temas de humanidades e ética em } \\
\text { currículo médico integrado em escola pública } \\
\text { no Distrito Federal, Brasil }\end{array}$ \\
\hline 14 & 2010 & $\begin{array}{l}\text { Revista Ciência e } \\
\text { Saúde Coletiva }\end{array}$ & RIOS, Izabel Cristina. & $\begin{array}{c}\text { Humanidades e medicina: razão e sensibilidade } \\
\text { na formação médica }\end{array}$ \\
\hline 15 & 2010 & $\begin{array}{l}\text { Revista Brasileira de } \\
\text { Educação Médica }\end{array}$ & $\begin{array}{l}\text { BINZ, Mara Cristina; FILHO, } \\
\text { Walter de Menezes; SAUPE, } \\
\text { Rosita. }\end{array}$ & $\begin{array}{l}\text { Novas tendências, velhas atitudes: as distâncias } \\
\text { entre valores humanísticos e inter-relações } \\
\text { observadas em um espaço docente e assistencial }\end{array}$ \\
\hline 16 & 2010 & $\begin{array}{l}\text { Revista Brasileira de } \\
\text { Educação Médica }\end{array}$ & $\begin{array}{l}\text { DALTRO, Mônica Ramos; } \\
\text { BUENO, Gabriela. }\end{array}$ & $\begin{array}{l}\text { Ludicidade e narrativa: estratégias de } \\
\text { humanização na graduação médica }\end{array}$ \\
\hline 17 & 2010 & $\begin{array}{l}\text { Revista Brasileira de } \\
\text { Educação Médica }\end{array}$ & $\begin{array}{l}\text { JUCÁ, Natalia Braga } \\
\text { Hortêncio et al. }\end{array}$ & $\begin{array}{c}\text { A Comunicação do diagnóstico “sombrio" na } \\
\text { relação médico-paciente entre estudantes de } \\
\text { medicina: uma experiência de dramatização na } \\
\text { educação médica }\end{array}$ \\
\hline 18 & 2011 & $\begin{array}{l}\text { Interface - } \\
\text { Comunicação, Saúde, } \\
\text { Educação }\end{array}$ & $\begin{array}{l}\text { RIOS, Izabel Cristina; } \\
\text { SCHRAIBER, Lilia Blima. }\end{array}$ & $\begin{array}{l}\text { Uma relação delicada: estudo do encontro } \\
\text { professor-aluno }\end{array}$ \\
\hline 19 & 2011 & $\begin{array}{l}\text { Revista Brasileira de } \\
\text { Medicina }\end{array}$ & $\begin{array}{l}\text { PINHEIRO, Thais R. S. P.; } \\
\text { BENEDETTO, Maria A. C.; } \\
\text { BLASCO, Pablo G. }\end{array}$ & $\begin{array}{l}\text { Ambulatório didático de cuidados paliativos: } \\
\text { aprendendo com os nossos pacientes }\end{array}$ \\
\hline 20 & 2012 & Revista de Medicina & $\begin{array}{l}\text { GALLIAN, Dante Marcello } \\
\text { Claramonte. }\end{array}$ & $\begin{array}{l}\text { Literatura e formação humanística em } \\
\text { medicina: o experimento do laboratório de } \\
\text { humanidades da EPM/UNIFESP }\end{array}$ \\
\hline 21 & 2012 & $\begin{array}{l}\text { Revista Brasileira de } \\
\text { Educação Médica }\end{array}$ & $\begin{array}{l}\text { MELLO, Denise Ribeiro } \\
\text { Barreto et al. }\end{array}$ & $\begin{array}{l}\text { Alçando voo: a experiência de ampliar o } \\
\text { diálogo entre psicologia e medicina }\end{array}$ \\
\hline 22 & 2012 & $\begin{array}{l}\text { Revista Brasileira em } \\
\text { Promoção da Saúde }\end{array}$ & MOTA, Gabriela Maia et al. & $\begin{array}{c}\text { A Percepção dos estudantes de graduação sobre } \\
\text { a atuação do "doutor palhaço" em um hospital } \\
\text { universitario }\end{array}$ \\
\hline 23 & 2012 & $\begin{array}{l}\text { Revista Brasileira de } \\
\text { Educação Médica }\end{array}$ & $\begin{array}{l}\text { RIOS, Izabel Cristina; } \\
\text { SCHRAIBER, Lilia Blima. }\end{array}$ & $\begin{array}{l}\text { A Relação professor-aluno em medicina - um } \\
\text { estudo sobre o encontro pedagógico }\end{array}$ \\
\hline 24 & 2012 & Revista de Medicina & $\begin{array}{l}\text { LUAMATO, Leandro Ryuchi } \\
\text { et al. }\end{array}$ & $\begin{array}{c}\text { Recital dos estudantes de medicina da } \\
\text { universidade de São Paulo (REMUSP): } \\
\text { descrição de um projeto musical de gestão, } \\
\text { comunicação e relacionamento dos acadêmicos } \\
\text { de medicina da faculdade de medicina da } \\
\text { universidade de São Paulo }\end{array}$ \\
\hline 25 & 2012 & $\begin{array}{l}\text { Revista Brasileira de } \\
\text { Educação Médica }\end{array}$ & $\begin{array}{l}\text { REBELLO, Maria Tereza M. } \\
\text { P.; NETO, João Felício } \\
\text { Rodrigues. }\end{array}$ & $\begin{array}{l}\text { A Humanização da assistência ao parto na } \\
\text { percepção de estudantes de medicina }\end{array}$ \\
\hline
\end{tabular}




\begin{tabular}{|c|c|c|c|c|}
\hline 26 & 2013 & $\begin{array}{l}\text { Revista Brasileira de } \\
\text { Educação Médica }\end{array}$ & $\begin{array}{l}\text { AYRES, José Ricardo de } \\
\text { Carvalho Mesquita et al. }\end{array}$ & $\begin{array}{l}\text { Humanidades como disciplina da graduação em } \\
\text { medicina }\end{array}$ \\
\hline 27 & 2013 & $\begin{array}{l}\text { Revista Brasileira de } \\
\text { Medicina }\end{array}$ & $\begin{array}{l}\text { BENEDETTO, Maria A. C.; } \\
\text { BLASCO, Pablo G.; } \\
\text { GALLIAN, Dante M. C. }\end{array}$ & $\begin{array}{l}\text { Narrativas de estudantes de medicina e } \\
\text { enfermagem: o que elas nos revelam? }\end{array}$ \\
\hline 28 & 2013 & $\begin{array}{l}\text { Revista Brasileira de } \\
\text { Educação Médica }\end{array}$ & FLOSS, Mayara et al. & $\begin{array}{l}\text { A Humanização através do programa recrutas } \\
\text { da alegria da FURG: um relato de experiência }\end{array}$ \\
\hline 29 & 2014 & $\begin{array}{l}\text { Revista Brasileira de } \\
\text { Educação Médica }\end{array}$ & $\begin{array}{l}\text { CAMARGO, Aline; } \\
\text { ALMEIDA, Aparecida S.; } \\
\text { MORITA, Ione. }\end{array}$ & $\begin{array}{c}\text { Ética e bioética: o que os alunos do sexto ano } \\
\text { médico têm a dizer }\end{array}$ \\
\hline 30 & 2014 & $\begin{array}{l}\text { Revista Brasileira de } \\
\text { Educação Médica }\end{array}$ & $\begin{array}{l}\text { FERREIRA, Debora Carvalho } \\
\text { et al. }\end{array}$ & $\begin{array}{l}\text { A Experiência do adoecer: uma discussão sobre } \\
\text { saúde, doença e valores }\end{array}$ \\
\hline 31 & 2014 & $\begin{array}{l}\text { Revista Brasileira de } \\
\text { Educação Médica }\end{array}$ & $\begin{array}{l}\text { TAKAHAGUI, Flavio Mitio } \\
\text { et al. }\end{array}$ & $\begin{array}{c}\text { MadAlegria - estudantes de medicina atuando } \\
\text { como doutores-palhaços: estratégia útil para } \\
\text { humanização do ensino médico? }\end{array}$ \\
\hline 32 & 2014 & $\begin{array}{l}\text { Revista Brasileira de } \\
\text { Educação Médica }\end{array}$ & ROSEVICS, Leticia et al. & $\begin{array}{c}\text { ProCura - a arte da vida: um projeto pela } \\
\text { humanização na saúde }\end{array}$ \\
\hline 33 & 2014 & $\begin{array}{l}\text { Revista Brasileira de } \\
\text { Educação Médica }\end{array}$ & $\begin{array}{l}\text { SOARES, Márcia Oliveira } \\
\text { Mayo et al. }\end{array}$ & $\begin{array}{c}\text { Reflexões contemporâneas sobre anamnese na } \\
\text { visão } \\
\text { do estudante de medicina }\end{array}$ \\
\hline 34 & 2015 & $\begin{array}{l}\text { Revista Brasileira de } \\
\text { Educação Médica }\end{array}$ & $\begin{array}{l}\text { RIOS, Izabel Cristina; } \\
\text { SIRINO, Caroline Braga. }\end{array}$ & $\begin{array}{l}\text { A Humanização no ensino de graduação em } \\
\text { medicina: o olhar dos estudantes }\end{array}$ \\
\hline 35 & 2015 & $\begin{array}{l}\text { Revista Brasileira de } \\
\text { Educação Médica }\end{array}$ & $\begin{array}{l}\text { AMORIM, Karla Patrícia } \\
\text { Cardoso et al. }\end{array}$ & $\begin{array}{l}\text { Mediarte com amor e humor: uma experiência a } \\
\text { partir do olhar dos participantes }\end{array}$ \\
\hline 36 & 2016 & $\begin{array}{l}\text { Interface - } \\
\text { Comunicação, Saúde, } \\
\text { Educação }\end{array}$ & $\begin{array}{l}\text { MARTINS, Ana da Fonseca; } \\
\text { BELLODI, Patrícia Lacerda. }\end{array}$ & $\begin{array}{l}\text { Mentoring: uma vivência de humanização e } \\
\text { desenvolvimento no curso médico }\end{array}$ \\
\hline 37 & 2016 & $\begin{array}{l}\text { Revista Brasileira de } \\
\text { Educação Médica }\end{array}$ & RIOS, Izabel Cristina. & $\begin{array}{l}\text { Humanidades médicas como campo de } \\
\text { conhecimento em medicina }\end{array}$ \\
\hline 38 & 2016 & $\begin{array}{l}\text { Revista Brasileira de } \\
\text { Educação Médica }\end{array}$ & $\begin{array}{l}\text { SILVA, Marlon R.; } \\
\text { GALLIAN, Dante M. C.; } \\
\text { SCHOR, Paulo. }\end{array}$ & $\begin{array}{l}\text { Literatura e humanização: uma experiência } \\
\text { didática de educação humanística em saúde }\end{array}$ \\
\hline 39 & 2016 & $\begin{array}{l}\text { Revista Trabalho } \\
\text { Educação e Saúde }\end{array}$ & $\begin{array}{l}\text { REGINATO, Valdir; } \\
\text { BENEDETTO, M. A. C.; } \\
\text { GALLIAN, Dante M. C. }\end{array}$ & $\begin{array}{l}\text { Espiritualidade e saúde: uma experiência na } \\
\text { graduação em medicina e enfermagem }\end{array}$ \\
\hline
\end{tabular}

Uma experiência de integração Ensino, serviço e comunidade de alunos do curso de graduação em medicina na atenção básica no município de Maceió-AL, Brasil

\begin{tabular}{ccccc}
\hline 412017 & $\begin{array}{c}\text { Revista Brasileira de } \\
\text { Educação Médica }\end{array}$ & $\begin{array}{c}\text { BALDI, Larissa; LINS, } \\
\text { Liliane; MENEZES, Marta } \\
\text { Silva. }\end{array}$ & $\begin{array}{c}\text { A Literatura como estratégia para reflexões } \\
\text { sobre humanismo e ética no curso médico: um } \\
\text { estudo } \\
\text { Qualitativo }\end{array}$ \\
\hline 42 & 2018 & $\begin{array}{c}\text { Revista de } \\
\text { Enfermagem do } \\
\text { Centro-Oeste Mineiro }\end{array}$ & $\begin{array}{c}\text { SILVA, Alexandre E.; } \\
\text { SOUSA, Paulo A.; RIBEIRO, } \\
\text { Renato F. }\end{array}$ & $\begin{array}{c}\text { Comunicação de notícias difíceis: percepção de } \\
\text { médicos que atuam em oncologia }\end{array}$ \\
\hline
\end{tabular}

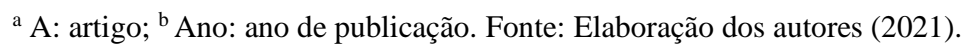


Figura 1 - Distribuição temporal das publicações selecionadas para revisão sobre Humanização na Educação Médica no Brasil, 2018.

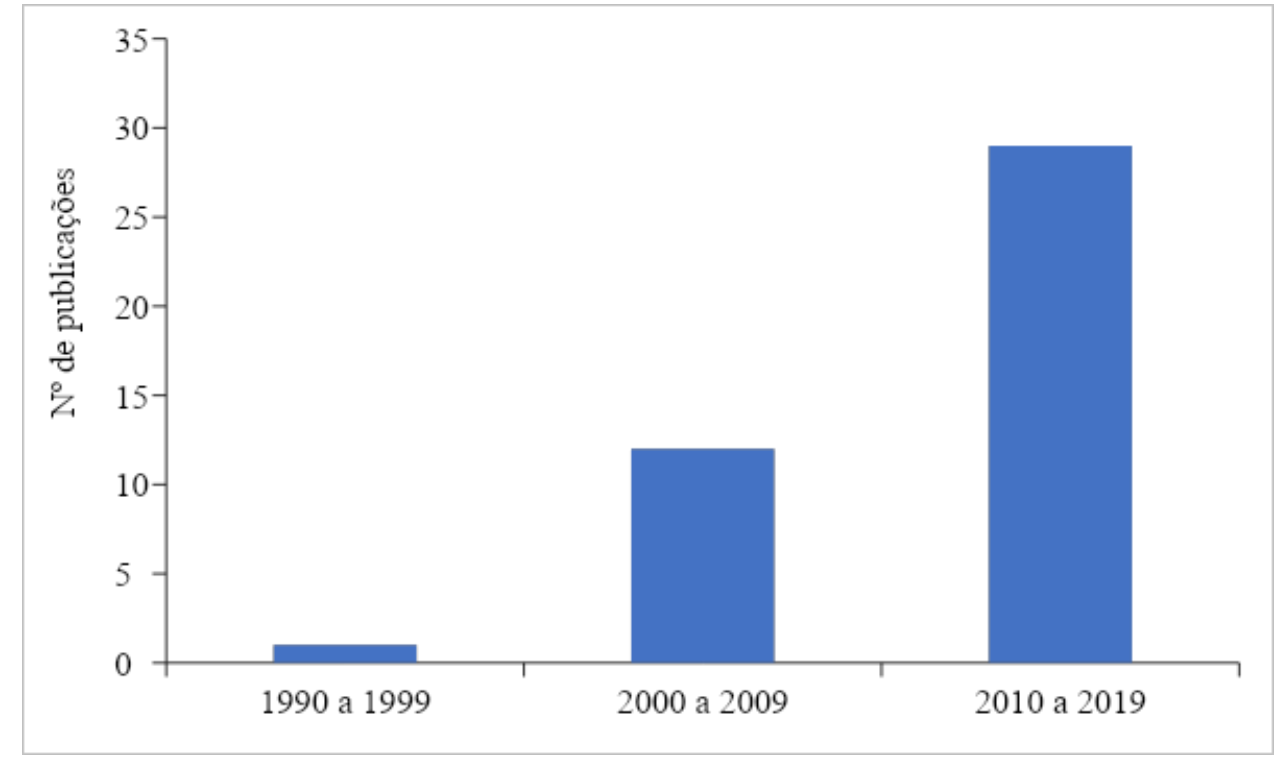

Fonte: Elaboração dos autores (2021).

Com relação aos tipos de estudos, constatou-se que a maior parte deles seguiram duas tendências: predominaram os exploratórios descritivos $(38 \%$; $\mathrm{n}=16)$, seguidos por relatos de experiência $(28,57 \%$; $\mathrm{n}=12)$. No que se refere à abordagem metodológica, destaca-se a realização de estudos qualitativos $(90,47 \%$; n=38), sugerindo que o tema da humanização é complexo e requer uma compreensão ampliada, a qual geralmente é alcançada por meio de estudos desta natureza. Há, ainda, um estudo quali-quantitativo e três estudos quantitativos.

Ainda, na análise dos estudos, constatou-se que 47,6\% $(n=20)$ deles foram realizados em cenários universitários, o que condiz com a realização de pesquisas envolvendo os estudantes como atores fundamentais no âmbito do debate sobre humanização na educação médica.

\subsection{Conceito atribuído ao termo humanização na educação médica}

Fazem parte dessa categoria três subcategorias, que auxiliam na compreensão dos conceitos atribuídos à humanização na educação médica presentes na literatura científica. A primeira subcategoria agrega estudos que relacionam a humanização na educação médica ao conceito adotado pela Política Nacional de Humanização (PNH), com foco na escuta, empatia, vínculo, ambiência e comunicação, conforme Brasil (2004) Já a segunda subcategoria abrange a humanização na educação médica fazendo referência à integralidade e envolvendo o trabalho em equipe, a cultura, a visão social e emocional. Por fim, a última subcategoria atribui ao conceito de humanização na educação médica sentidos ligados à garantia de direitos, ética e responsabilidade social.

\subsubsection{Conceitos relacionados à Política Nacional de Humanização}

Fazem parte desta subcategoria os estudos: A1, A7, A8, A9, A10, A11, A12, A14, A15, A16, A17, A19, A21, A22, A24, A25, A27, A30, A31, A32, A33, A36, A37, A38, A39, A40 e A42, totalizando 64,28\% (n=27) dos artigos.

A PNH possui o propósito de acrescentar qualidade na atenção e na gestão do SUS. Ela tem o objetivo de promover a comunicação entre gestores, trabalhadores e usuários, buscando a valorização, criação de vínculos, comunicação, inserindo mudanças na forma de agir e de cuidar do próximo conforme Brasil (2004). 
Da análise dos estudos, observou-se que 26,19\% (n=11) (A9, A14, A15, A16, A17, A24, A30, A31, A33, A40 e A42) indicaram uma concepção de humanização com base na escuta, comunicação, visão holística do indivíduo e boa relação médicopaciente. Além disso, juntamente com outros quatro artigos (A1, A11, A36 e A37), totalizando 35,71\% (n=15) dos estudos, evidenciaram que a humanização na educação médica está relacionada à empatia com o paciente e seus familiares. Os estudos demonstram a importância de os profissionais compreenderem que a pessoa que se apresenta ao serviço de saúde é um ser humano, que deve ser visto para além de suas queixas e sintomas.

Ao encontro disso, Benedetto e Gallian (2018) mostraram em seu estudo que a empatia é considerada uma boa prática em saúde, em que o olhar ao paciente deve ser ampliado, possibilitando ao profissional se colocar no lugar do outro, acolhendoo como ele próprio gostaria de ser tratado. Gouveia et al. (2017) também afirmam que uma dimensão essencial da humanização é a empatia, por possibilitar desenhar caminhos para a criação e o desenvolvimento de vínculo entre o profissional e a pessoa, facilitando a evolução do atendimento.

Nesse sentido, os artigos A7, A8, A21, A38 e A42 discutem a importância da criação de vínculo para que o processo saúde-doença seja compreendido de forma abrangente, garantindo-se, assim, uma boa qualidade assistencial. Mônaco (2010) propõe que a medicina deve ser feita por vocação, ou seja, que é esperado, dos estudantes, o desenvolvimento de outras habilidades para além das técnicas no processo de se tornarem médicos, com vistas a uma atuação humanizada na relação com os sujeitos de seu fazer profissional. Para o autor, ser um profissional humano é construir vínculo empático, percebendo o paciente como um todo e buscando, a cada encontro, maior afetividade. Também, para Maeyama et al. (2016), uma assistência adequada é a que adota uma abordagem cuidadosa para com o paciente, tratando o problema e evidenciando que o foco da atenção não está somente na doença, mas centrado no cuidado com o indivíduo que a apresenta. Isso converge com a visão de Albuquerque (2015), quando afirma que a criação de vínculos com foco no diagnóstico, diminuição do sofrimento e reabilitação são pontos-chave para a assistência médica.

Outros estudos, como A9, A14, A15, A16, A17, A24, A30, A31, A33, A40 e A42, afirmam que a escuta é componente da humanização. Na mesma direção, Nilson et al. (2018) indicaram que a escuta aos problemas de saúde do usuário é uma resposta qualificada e positiva ao paciente, sendo uma possibilidade de o profissional se responsabilizar com a resolução do problema. Além disso, Sousa, Gallian e Maciel (2012) conceituam um =médico excelente‘ como o profissional capaz de escutar o paciente com o cuidado que lhe é de direito. Já Garcia et al. (2010) reiteram que as vivências que mais contribuem para a formação médica são aquelas baseadas na observação de consultas, cuja principal finalidade seja a escuta.

Nos estudos A9, A14, A15, A16, A17, A24, A30, A31, A33, A40 e A42, a humanização na educação médica é também considerada como uma adequada comunicação entre profissional e usuário. Assim, conforme Amorim e Bedaque (2018), a prática de comunicação propicia confiança, superação da timidez e criação de vínculos que são essenciais para o levantamento de informações desejadas sobre os usuários.

Nos estudos A19, A27 e A39, os autores sugerem que compreender o cenário em que o paciente vive e entender que uma das premissas da humanização é a capacidade de o profissional construir uma relação de compaixão com esse outro, que demanda seu fazer médico, são ferramentas fundamentais para um bom cuidado. Também, para A12, A22 e A25, um dos critérios indispensáveis da humanização fundamenta-se no adequado acolhimento individual, reconhecendo a crescente necessidade de uma relação de contato direto entre profissional de saúde e paciente.

Dessa forma, Nilson et al. (2018) corroboram essas ponderações, à medida que conceituam a humanização como compaixão, considerando-a essencial na prática do acolhimento. A compaixão possibilita a avaliação de riscos e vulnerabilidades do paciente, favorecendo o autocuidado e a solidariedade. Ademais, para Rios (2012), atitudes de compaixão e acolhimento, juntamente com uma adequada comunicação, diálogo e interação profissional-paciente, aprimoram o cuidado e a qualidade da 
atenção à saúde.

Os estudos A9, A14, A15, A16, A17, A24, A30, A31, A33, A40 e A42 refletem sobre a necessidade de uma visão holística do indivíduo, a fim de desenvolver uma boa relação médico-paciente. Ribeiro e Poles (2019) reforçam essa perspectiva, argumentando sobre a importância da sensibilidade frente ao sofrimento do paciente e de sua família, salientando um bom manejo no envolvimento com o usuário, de forma a tornar a relação médico-paciente confortável. Igualmente, Oliveira et al. (2017) remetem à postura de perceber o paciente antes da doença, não apenas para estabelecer uma relação médico paciente mais qualificada, mas também para ampliar a prática da humanização como um todo.

Por fim, A10 e A32 argumentam sobre o ambiente em que os pacientes devem ser recebidos, propondo que deveriam ser incluídos na formação médica alguns temas relativos ao processo de viver humano, como a noção de criar um ambiente confortável para geração e manutenção das reflexões. Mônaco (2010) refirma essa proposição, defendendo que uma boa prática clínica e uma equipe qualificada, que recebem os usuários em ambientes confortáveis, aconchegantes e arejados, fazendo com que se sintam acolhidos, são elementos que favorecem a criação e o fortalecimento de vínculos empáticos.

\subsubsection{Humanização para a integralidade}

Integram essa subcategoria conceitual conhecimentos como o trabalho em equipe, cultura, visão social e emocional. Nessa direção, os artigos incluídos nessa discussão são A3, A5, A7, A9, A10, A13, A15, A16, A17, A24, A25, A29, A33, A39 e A40, totalizando $35,71 \%$ ( $n=15)$ dos estudos analisados.

Inicialmente, é conveniente esclarecer que, de acordo com o princípio II do Art. 7 da Lei Orgânica n. 8.080/90, a integralidade da assistência é entendida como um conjunto articulado e contínuo das ações e serviços preventivos e curativos, individuais e coletivos, exigidos para cada caso em todos os níveis de complexidade do sistema de saúde conforme Brasil (2008).

A esse propósito, conforme os artigos A5, A7, A9, A10, A15, A16, A25 e A40, o trabalho em equipe contribui para a humanização na atenção à saúde na medida em que favorece o acolhimento, o que é corroborado por Arias (2006). Segundo os autores desses estudos, o trabalho em equipe multiprofissional promove o acolhimento - conforme previsto no conceito de humanização apresentado pela PNH - e proporciona um cuidado integral para o paciente e sua família. Já para Arias (2006), a contribuição do trabalho em equipe para a humanização na atenção à saúde reside na promoção do acolhimento, mas especialmente porque ele interfere positivamente na boa relação médico-paciente.

Além disso, em A5, A13, A17, A33 e A39, os autores postulam que a integralidade, embora não signifique totalidade, consiste em cuidar do indivíduo em toda a complexidade humana, ou seja, em suas dimensões física, mental, emocional e cultural. Nessa lógica, o debate - em A5, A13, A17, A33 e A39 - assume um ponto de vista complementar ao que é discutido por Kipper e Loch (2002), uma vez que para esses autores a integralidade está pautada no processo de saúde-doença, nos níveis de atenção, promoção, prevenção, recuperação e reabilitação.

Para A9 e A39, a humanização na educação médica deve englobar a espiritualidade. Os autores defendem que abordar a espiritualidade é importante e necessário na formação profissional para que os estudantes compreendam que crenças espirituais e culturais compõem uma dimensão essencial da saúde e do bem-estar da maior parte dos usuários de seus serviços. Afirmam ainda, que, ao refletirem sobre essas questões, os futuros profissionais em processo de formação conseguirão reconhecer, inclusive, que sua própria espiritualidade interfere nos cuidados que prestam aos usuários.

Chaves e Santos (2017) e Zanetti et al. (2018) corroboram essas ponderações. Para esses autores, debruçar-se sobre o tema da espiritualidade no processo de ensino aprendizagem pode ser um vetor relevante da humanização na educação médica. Contudo - acrescentam os autores -, uma formação pautada na perspectiva da humanização é especialmente favorecida quando o debate da espiritualidade é complementado pelo da religiosidade, explorando temas ligados, por exemplo, às crenças de cura, 
com o objetivo de que o médico saiba ajudar o paciente a lidar, manejar e adaptar-se a sua enfermidade para enfrentá-la.

Os artigos A24, A25 e A29 propõem que a Filosofia, a Sociologia e a Antropologia fazem parte do ensino sobre a humanização na educação médica. O estudo de conteúdos dessas áreas, entre outras, promove a formação de profissionais e, consequentemente, a prestação de serviços humanizados. Esses estudos remetem, ainda, à importância que deve ser dada, também, ao cuidado dos cuidadores da saúde, de forma que estejam saudáveis para que possam cuidar do outro.

Esses autores, juntamente com os de A16 e A39, argumentam que a humanização pode ser caracterizada pela medicina científica, aquela que aborda o ser humano valorizando a sua cultura, sua vida social e seu emocional. De acordo com Marco et al. (2013), a Filosofia, a Sociologia e a Antropologia oferecem elementos para o desenvolvimento de atitudes e comportamentos pautados pela ética e pela moral, compondo, assim, uma formação para a humanização.

Para os autores de A3, promover a discussão sobre o uso apropriado da tecnologia na educação médica contribui para uma atenção mais humanizada, na medida em que desenvolve um saber usufruir dessa tecnologia de forma consciente e construtiva. Essa ideia condiz com as de Filho, Dias e Toledo (2018), que referem em seu estudo que a humanização está relacionada ao uso competente da tecnologia - não só a digital, mas também naquela que deriva da aplicação de conhecimentos científicos -, definindo que a qualificação do trabalho profissional está assentada no saber-ser tanto quanto no saber-fazer. Em contrapartida, para Oliveira, Castanho e Oliveira (2019), o avanço intenso da tecnologia tem desestruturado a relação médicopaciente, aumentando apenas a qualidade da educação médica, enquanto fragiliza o processo de igualdade social.

\subsubsection{Humanização como possibilidade de garantir direitos aos usuários}

Estão inclusos nessa subcategoria A2, A3, A9, A10, A13, A16, A17, A18, A20, A23, A24, A25, A26, A28, A29, A32, A33, A34, A35, A37, A39 e A41, totalizando 52,38\% (n=22) dos artigos analisados.

Inicialmente, convém registrar que, conforme o Art. $2^{\circ}$ da Carta dos Direitos dos Usuários da Saúde, toda pessoa tem direito ao acesso a bens e serviços ordenados e organizados para garantia da promoção, prevenção, proteção, tratamento e recuperação da saúde conforme Brasil (2012). Adicionalmente, o Código de Ética Médica refere que os médicos em exercício da profissão devem seguir as normas estabelecidas por este código, inclusive nas atividades relativas a ensino, pesquisa e administração de serviços de saúde, bem como em quaisquer outras que utilizem o conhecimento advindo do estudo da medicina conforme Brasil (2019)

A esse respeito, nesta revisão, observou-se que 38\% (n=16) dos estudos (A2, A9, A10, A16, A18, A20, A23, A24, A26, A28, A29, A32, A33, A35, A39 e A41) relacionam a humanização na educação médica com a ética profissional. Para seus autores, os valores garantidos pelo Código de Ética Médica - beneficência, confiabilidade, honestidade, humildade, justiça, paciência, respeito, responsabilidade e solidariedade - devem fazer parte da formação se o que se pretende é uma atuação humanizada do futuro profissional.

Corroborando as proposições desses autores, Rios (2009) afirma que o objetivo é a formação de profissionais generalistas, críticos, reflexivos e humanistas, que sejam capazes de construir relações médico-paciente adequadas, permeadas pela ética e pela responsabilidade. Santos, Lins e Menezes (2018) também argumentam que a ética e a bioética podem ser recursos de aprendizagem desenvolvidos por meio da literatura e da abordagem de temas que os estudantes vivenciam no decorrer da formação, e não apenas com base no Código de Ética Médica. Dessa forma, romances, teatro, poesias e filmes podem auxiliar no desenvolvimento de conhecimento intuitivo para a formação humanística do futuro profissional. De acordo com A3, A17 e A23, a humanização na educação médica deve abranger o respeito aos direitos humanos, considerando a vontade do paciente, o que inclui seu direito a ser informado sobre seu diagnóstico e sobre todas as condutas terapêuticas adotadas, bem como sua anuência em relação a elas. Logo, para estes autores, a qualificação da atenção, envolvendo preocupações, respeito e promoção 
assistencial, são direitos de todos os usuários. No mesmo sentido, Kreischer et al. (1996) afirmam que o direito à individualidade, ao sigilo profissional, à participação do paciente no planejamento do tratamento e o direito a discutir sobre seu quadro clínico e sua evolução constituem uma qualificação da atenção adequada. Blank e Brauner (2009) afirmam, também, que o direito humano envolve garantir ao paciente o acesso à informação, aconselhando-o principalmente sobre o abuso de medicações, considerando seus direitos de consumidor.

Adicionalmente, A25 e A34 abordam a humanização sob a perspectiva específica do parto e puerpério, que consiste no direito de escolha das mulheres acerca de seus diagnósticos e tratamentos, cabendo a elas a decisão sobre a adesão às orientações médicas. Nomeadamente no estudo A34, o autor aborda a importância da permissão de acompanhante no parto, contribuindo para a tranquilidade da gestante. Além disso, a humanização significa evitar toda e qualquer forma de violência institucional contra a saúde da mulher, respeitando-a em todas as suas decisões.

Nesse sentido, Barbosa et al. (2009) conceituam a humanização do parto como um processo de respeito à individualidade feminina, que oportuniza uma assistência que contempla sua cultura, crença, valores e opiniões. Silva et al. (2014) relatam que existe, ainda, negligência, despreparo e imperícia na prática profissional obstétrica. A falta de preparo institucional hospitalar também é considerada uma violência ao parto humanizado, pois, muitas vezes, ocorre o desrespeito dos direitos humanos das gestantes, materializado, por exemplo, como uso de medicações indevidas, episiotomias desnecessárias e manobras para acelerar o parto sem justificativa.

Por fim, para os autores de A13, A17, A32 e A37, a humanização não é uma questão que pode ser adiada, relegada para quando o médico já tiver desenvolvido seu modo de ser profissional. Ao contrário, a humanização deve começar a ser tratada desde o ambiente de ensino, ainda na universidade. Essas ponderações convergem com as de Gonzalez e Branco (2012) e as de Garcia et al. (2014), que propõem que a compreensão da humanização deve se apoiar na responsabilidade social, buscando-se entender a demanda do paciente, reconhecendo e respeitando sua vontade e seu direito de ser informado sobre seu estado de saúde e, ainda, procurando responder a seus questionamentos sem preconceitos ou juízos de valor.

\subsection{Estratégias pedagógicas utilizadas pelos cursos de graduação em medicina}

As estratégias pedagógicas identificadas nos estudos analisados foram classificadas em duas subcategorias: estratégias extramuros e estratégias intramuros. Na subcategoria extramuros, são apresentados e discutidos os estudos cujas estratégias pedagógicas inserem os estudantes na realidade, isto é, são realizadas em cenários reais de prática. Já na subcategoria intramuros, estão compreendidos os estudos cujas estratégias referidas são realizadas no cotidiano dos processos de ensino-aprendizagem desenvolvidos na universidade, em sala de aula, etc.

\subsubsection{Estratégias pedagógicas extramuros}

Estão inclusos nessa subcategoria os artigos A1, A2, A3, A5, A6, A7, A8, A9, A11, A15, A16, A19, A22, A23, A24, A25, A26, A27, A28, A29, A31, A32, A33, A35, A36, A37, A39, A40 e A42, perfazendo 60,04\% (n=29) dos estudos selecionados para esta pesquisa. As estratégias pedagógicas referidas nos artigos que se caracterizam pela inserção dos estudantes na realidade têm relação com o desenvolvimento de portfólios, narrativas, atividades teórico práticas, atividades lúdicas em hospitais, vivências em cenários reais, estágios, visitas domiciliares, questionários, grupo focal, pesquisas e entrevistas a campo. Do total de artigos analisados, 11,9\% (A16, A19, A26, A27 e A39) relataram, como estratégia pedagógica para o desenvolvimento da humanização na educação médica, a medicina baseada em narrativa, isto é, fundamentada na reflexão dos estudantes sobre os discursos de pacientes e familiares. Nesse sentido, A26, A27 e A39-com base nas atividades desenvolvidas 
a partir de uma disciplina eletiva, na qual os estudantes realizavam a discussão das narrativas dos pacientes com seus professores - propõem que, para um cuidado mais humanizado, é essencial a escuta do paciente e de seus familiares.

Já A19 é um estudo sobre as atividades de acadêmicos que atuavam em um ambulatório de cuidados paliativos e que, ao final das consultas, debatiam sobre o atendimento médico-estudantil com seus preceptores. O estudo reafirma a importância do encorajamento dos membros da família para lidarem com a doença do paciente e a necessidade de apoiar os estudantes frente a situações em que é preciso comunicar notícias difíceis aos usuários. Na mesma direção, A16 resulta de um estudo com narrativa biográfica, buscando compreender os processos psicológicos típicos do envelhecimento humano. Benedetto e Gallian (2018) confirmam as potencialidades do uso de narrativas para o ensino da humanização na educação médica. Os autores asseguram que o fundamento da medicina baseada em narrativa consiste em escutar as histórias dos pacientes com empatia, mesmo aquelas que, aparentemente, não guardem relação com suas histórias clínicas. Em A22, A31, e A35 foram realizadas atividades lúdicorecreativas com pacientes internados em hospitais, favorecendo o entendimento sobre a necessidade da atenção e da comunicação com esses indivíduos debilitados. Os estudos apontam que a utilização dessas estratégias pedagógicas contribui para o enfrentamento da doença por parte dos pacientes. Já para os estudantes, possibilita o desenvolvimento de sua afetividade no trato com os usuários. Também, em A28 e A32, os estudantes, por meio de projeto de extensão, realizaram atividades lúdicas em hospitais e na comunidade, com o objetivo de interagir e aproximar estudantes e usuários. No âmbito de A24, foi relatada uma atividade com um grupo de estudantes que se reuniram para organizar um recital, a fim de realizar apresentações musicais em hospitais, o que visava à integração e à aprendizagem da comunicação para formar profissionais mais humanizados.

Convergindo com as ponderações desses estudos, Nehmy et al. (2009) afirmam que atividades lúdico-recreativas em hospitais contribuem para promover mudanças na educação médica, favorecendo a formação de profissionais humanistas e éticos. Os autores referem, ainda, que tais atividades evidenciam a importância do contato com o paciente, percebendo-o como um ser holístico.

Além disso, em A11, para o ensino da humanização, fez-se uso do cinema em uma atividade extracurricular optativa, tomada como estratégia pedagógica, realizando associação com temas como conceito de saúde e doença, trabalho multidisciplinar e fases do ciclo vital. Filho, Dias e Toledo (2018) afirmam que a ludicidade dessa manifestação permite aos alunos identificarem, nos filmes, situações que remetem à sua vivência. Incentivam, além da reflexão, o desenvolvimento pessoal e profissional sobre as formas de comunicação e de percepção do outro, a maneira de se relacionar com docentes e pacientes, além de aprender sobre o respeito e empatia.

Nos artigos A3, A5, A7, A36, A37 e A40 foram referidas estratégias pedagógicas baseadas nos primeiros contatos dos estudantes com os pacientes, pelo acompanhamento das práticas dos preceptores ou pela realização de plantões de forma voluntária para obter maior experiência prática e aperfeiçoar a aprendizagem da relação médico-paciente. Zeni (2014) assegura que metodologias ativas, que buscam desenvolver os aspectos cognitivos, procedimentais e atitudinais nos acadêmicos, nas quais os protagonistas são os próprios alunos, objetivam estimular o desenvolvimento de habilidades por meio do contato com a realidade e o sofrimento humano. Seguindo a mesma perspectiva, Garcia, Ferreira e Ferronato (2012) asseguram que estar em situações que mimetizam a futura rotina da profissão funciona como um estímulo para o aprofundamento do estudo, além de possibilitar a vivência e o aprendizado da relação médico-paciente em suas exigências comportamentais, éticas e de habilidades.

Ademais, conforme relatado em A40, visitas domiciliares se mostraram estratégias pedagógicas importantes para o fortalecimento do conhecimento humanístico dos futuros profissionais, na medida em que proporcionam que os estudantes vivenciem experiências positivas e negativas com pacientes reais fora de centros hospitalares, conhecendo sua cultura, seus modos de viver e sua qualidade de vida. No mesmo artigo, os autores utilizaram, como parte da estratégia pedagógica, a construção de portfólios pelos estudantes, como recurso para que refletissem sobre seu aprendizado no âmbito da humanização. 
Poles et al. (2018) alegam que as visitas domiciliares são habitualmente encaradas como de menor relevância para as tomadas de decisão e adoção de condutas. Entretanto, as visitas domiciliares são fundamentais no sentido do atendimento e da promoção da saúde. Os autores julgam que este é mais um aspecto importante a ser considerado pelos professores e revisto no âmbito dos projetos pedagógicos dos cursos de medicina. Ainda, Nogueira et al. (2017), nesse contexto, atestam que os acadêmicos, por meio da experiência com as ferramentas de avaliação em saúde, visitas domiciliares e processo de construção de vínculo, constroem uma compreensão ampla da dinâmica familiar, fortalecendo sua capacidade de reconhecimento das particularidades do grupo familiar acompanhado, sendo importantes para sua formação acadêmica.

A estratégia pedagógica relatada por A6, A8, A29 e A33 fundamentou-se na aplicação de questionários a estudantes de medicina e médicos em contextos diversos, como hospitais-escola, ambulatórios, pronto-socorro e enfermarias. Daltro e Bueno (2010) afirmam que, ao se realizar a análise de questionários, o passo inicial deve ser a busca pelas relações que já se encontravam implícitas nas questões formuladas pelo entrevistador, de forma a definir os domínios culturais estudados.

Nesse contexto, a análise dos dados dos questionários de A6, A8, A29 e A33 proporcionou conhecer o entendimento dos participantes sobre a humanização no ensino e nas práticas médicas. Enquanto A6 e A29 focaram nas práticas dos docentes, A33 se dedicou à compreensão da anamnese por meio da abordagem biopsicossocial-ambiental. Já A8 procurou detectar dificuldades existentes para os estudantes durante a graduação. Apesar de abordagens distintas, todos os estudos declararam o objetivo de contribuir para o ensino e a aprendizagem da integralidade, com base na formação de profissionais éticos em todos os níveis de atenção e nas fases do processo saúde-doença.

Estudos desenvolvidos por meio de entrevistas foram realizados por A1, A2, A23, A25 e A42. Os artigos A1 e A2 trataram de critérios emocionais, demonstrando a necessidade do controle de suas próprias emoções por parte do profissional, devendo ser trabalhada ainda na formação estudantil. Em A1, especificamente, os autores concluíram a necessidade de introduzir discussões sobre a morte e o morrer no processo de educação médica. Por sua vez, A23 explorou a relação docente-discente, analisando condutas no ensino e o predomínio da ética e da competência relacional. Ademais, A25 enfatizou a humanização da assistência ao parto, por meio da comunicação com preceptores e estudantes, o que torna o acolhimento essencial. Já A42 tomou como contexto a prática oncológica, abordando a comunicação de notícias difíceis e como enfrentá-las no âmbito da profissão médica.

Nessa perspectiva, destaca-se que, para Rios e Sirino (2015), a técnica de entrevistas é uma estratégia eficiente pela possibilidade de obter relatos vívidos e aprofundados sobre o tema. Taquette e Minayo (2015) defendem também que a melhor maneira de ensinar os alunos é realizar entrevistas em profundidade. Os autores mostram que elas incentivam os alunos a ouvir com atenção seus interlocutores e, consequentemente, melhoram sua prática de investigação, em especial na elaboração de perguntas.

Além disso, A9 traz, como estratégia pedagógica, a técnica de grupo focal, explorando a experiência do estudante em contato com o paciente, a capacitação dos professores e a postura ético-humanista de discentes e docentes dentro do hospital universitário. Maeyama et al. (2016) defendem essa estratégia pedagógica, pois declaram que a coleta de dados realizada por meio de grupo focal permite melhor contextualização do fato, por meio da criação de uma situação interativa entre os participantes, mais próxima do que uma entrevista individual.

Por fim, A15 foi o único artigo analisado cujo autor declarou a pesquisa como estratégia pedagógica, fazendo observações e registrando as atitudes cotidianas dos alunos em uma Unidade Básica de Saúde, para posterior análise e discussão dos apontamentos. Para Filho et al. (2018), a estratégia de pesquisa compreende a construção orientada do conhecimento, com base na problematização e em elementos da realidade concreta da prática laboral, tecnológica ou acadêmica. 


\subsubsection{Estratégias pedagógicas intramuros}

Integram esta subcategoria os estudos A4, A10, A11, A13, A14, A15, A18, A20, A21, A30, A31, A34, A38 e A41, totalizando 33,33\% (n=14) dos artigos analisados. Esses estudos dizem respeito às estratégias pedagógicas utilizadas no cotidiano das instituições de ensino, sendo elas: discussões de textos, trocas de idéias, casos fictícios e grupo focal.

Os estudos A30, A31, A34, A38 e A41 resultaram de situações de debates entre docentes e discentes, evidenciando a experiência dos acadêmicos e favorecendo a criação de vínculo entre os futuros profissionais. No entanto, A38 e A41 estiveram centrados em discussões realizadas a partir da leitura de livros, a fim de que os estudantes compreendessem os conceitos relativos à formação humanística. A discussão a partir de textos de livros, para Marco et al. (2013) e para Sousa, Gallian e Maciel (2012), tem por objetivo desenvolver a auto-observação, para que se aprenda a flexibilidade necessária para enfrentar os dilemas do diaa-dia da área profissional, além de ajudar a evoluir de forma empática.

Os artigos A34 e A31 compartilharam de proposta semelhante, porém, realizando um estudo em que a discussão, em sala, era feita a partir de vivências, com o objetivo de aprimorar o entendimento da humanização nas práticas médicas. A esse respeito, Nilson et al. (2018) argumentam que os debates a partir de vivências são essenciais para a formação acadêmica. Esse tipo de estratégia possibilita aos estudantes o entendimento do sentido de acolhimento, como o acesso universal e as necessidades pessoais de cada paciente, bem como a escuta qualificada e a criação de vínculo médico-paciente, o que contribui para o desenvolvimento de uma formação humanizada.

Outros sete artigos - A4, A13, A14, A18, A20, A21 e A30 - tiveram como estratégia pedagógica a discussão de casos. Contudo, A13, A18, A21 e A30 usufruíram da troca de ideias sobre casos clínicos fictícios para que os estudantes valorizassem a relação médico paciente. De outro modo, A4, A14 e A20 realizaram discussões com elaboração de estratégias que buscassem melhorar a inserção da humanização no ensino, notando que há fragmentações quando o assunto são as humanidades na instituição de ensino e no território.

Corroborando esses achados, Bartolo et al. (2017) também se baseiam em troca de ideias sobre casos clínicos fictícios por meio da disciplina de Habilidades Práticas. Essa atividade tem o objetivo de auxiliar na formação de futuros profissionais aptos a zelar pelo bem-estar dos pacientes, com um pensamento crítico e reflexivo, capazes de exercer uma boa relação médicopaciente. Em contrapartida, Oliveira, Castanho e Oliveira (2019) debateram com estudantes sobre o atendimento de pacientes pertencentes a populações marginalizadas socialmente ou em condições de vulnerabilidade, anunciando-o como essencial para melhorar a qualidade da humanização perante o ensino-aprendizagem, convergindo com as estratégias trazidas por A4, A14 e A20.

Nessa dinâmica das relações humanas, A11 e A15 utilizaram a dramatização como estratégia pedagógica. Ambos simularam a troca de papéis como recurso psicodramático, fundamentando-se no contexto de —como seriall caso os acadêmicos fossem os próprios pacientes. A ideia era que os estudantes se permitissem sentir as angústias, medos e ansiedades presentes no seu papel profissional, incluindo todos os aspectos que suas possibilidades criativas lhes permitissem, no intuito de compreender as tensões provocadas no exercício deste papel.

A esse propósito, Pereira et al. (2016) também basearam seu estudo na prática dramática, realizando troca de papéis entre estudantes, o que mostrou a necessidade de trabalhar a relação médico-paciente e o processo saúde-doença com vistas a desenvolver nesses futuros profissionais um saber lidar com a angústia e a ansiedade perante o paciente. Já Savaris et al. (2013) propõem que a dramatização na educação médica pode ser utilizada também com outros focos, como o ensino da bioética e da ética, por meio de atividades como júri simulado, oportunizando a discussão de assuntos deontológicos e bioéticos.

Por fim, A10 utilizou como estratégia pedagógica a técnica de grupo focal em sala de aula, analisando a relação estudantil com a instituição e a relação aluno-professor. Pereira et al. (2018) afirmam que a técnica de grupo focal possibilita 
discussões aprofundadas relacionadas a uma determinada temática de interesse comum dos participantes. Asseguram, ainda, que por meio dessas discussões, os participantes envolvidos na pesquisa buscam maior conhecimento em relação a determinado fenômeno e ampliam as possibilidades de mudanças de opiniões pré-concebidas.

\section{Conclusão}

Da análise dos estudos selecionados, constatou-se que o número de publicações que abordam o objeto de estudo desta revisão vem aumentando nos últimos anos, especialmente na última década, corroborando uma tendência crescente de fortalecer a humanização na educação médica frente ao reconhecimento de sua importância.

Além disso, observou-se que a humanização é um termo tratado de forma polissêmica na literatura, carregando princípios da Política Nacional de Humanização, da integralidade e da garantia de direitos. Também, em relação à incorporação da humanização nos processos de ensino-aprendizagem, percebeu-se que diferentes estratégias pedagógicas têm sido utilizadas com esse propósito, tanto no cotidiano das salas de aula universitárias quanto para além delas, nos cenários de práticas da educação médica. Pondera-se, a título de conclusão, que a humanização apresenta um potencial importante como ferramenta para a promoção da saúde e para o fortalecimento do SUS, embora, a partir dos estudos analisados, esses aspectos tenham sido pouco explorados, evidenciando lacunas a serem abordadas em pesquisas futuras sobre a temática. Sugere-se a realização de trabalhos que avaliem o bem estar do estudante de medicina.

\section{Referências}

Albuquerque, A. (2015). Os direitos humanos na formação do profissional de medicina. Revista de Medicina, 94(3), 169-178.

Almeida, N., Lopes, A. A., Coutinho, D. M., Cardoso, A. J., Santana, L. A., Santos, V. P., \& Oliveira-Lima, J. A. (2018). Formação Médica na UFSB: III. Aprendizagem Orientada por Problemas e Competências. Revista Brasileira de Educação Médica, 42, $129-141$.

Almeida, N., Lopes, A. A., Coutinho, D. M., Cardoso, A. J., Santana, L. A., Santos, V. P., \& Oliveira-Lima, J. A. (2018). Formação Médica na UFSB: III. Aprendizagem Orientada por Problemas e Competências. Revista Brasileira de Educação Médica, 42, 129-141.

Amorim, K. P., \& Bedaque, H. D. P. (2018). A percepção dos estudantes de medicina sobre a influência do Mediarte na educação médica. Revista Brasileira de Educação Médica, 42, 54-62.

Amorim, K. P. C., Rocha, A. K. C., Silva, I. C. D. S., Melo, L. M. B. D., \& Araújo, M. A. A. D. (2015). Mediarte com amor e humor: uma experiência a partir do olhar dos participantes. Revista brasileira de educação médica, 39, 294-301.

Amore, E. D., Dias, R. B., \& Toledo, A. C. D. C. (2018). Ações para a Retomada do Ensino da Humanização nas Escolas de Medicina. Revista Brasileira de Educação Médica, 42, 14-28.

Arias, E. H. L. (2006). Desafios na formação médica: o Programa Saúde da Família como prática de ensino. Rev. bras. med. fam. comunidade, 148-148.

Barbosa, I. S. (2009). Humanização da assistência ao parto. Trabalho de Conclusão de Curso (Pós-graduação em Saúde Coletiva e Saúde da Família) - Instituto de Ensino Superior de Londrina, Londrina.

Bartolo, E. B., Santos, M. A. P. D., DinatoI, M. C., \& Pinto, R. M. F. (2017). Humanidades médicas-metodologia utilizada no Curso de medicina do Centro universitário Lusíada (unilus). Revista Brasileira de Educação Médica, 41(3), 449-453.

Benedetto, M. A. C. D., \& Gallian, D. M. C. (2018). Narrativas de estudantes de Medicina e Enfermagem: currículo oculto e desumanização em saúde. InterfaceComunicação, Saúde, Educação. 67(22), 1197-1207

Bertoldi, S. G., Folberg, M. N., \& Manfroi, W. C. (2013). Psicanálise na educação médica: subjetividades integradas à prática. Revista Brasileira de Educação Médica, 37, 202-209.

Binz, M. C., Menezes Filho, E. W. D., \& Saupe, R. (2010). Novas tendências, velhas atitudes: as distâncias entre valores humanísticos e inter-relações observadas em um espaço docente e assistencial. Revista Brasileira de Educação Médica, 34, 28-42.

Binz, M. C. (2008). Revitalização da humanização no ensino médico.

Blank, D. M. P., \& Brauner, M. C. C. (2009). Medicalização da saúde: biomercado, justiça e responsabilidade social. JURIS-Revista da Faculdade de Direito, $14,7-24$.

Blasco, P. G. (2011). O humanismo médico: em busca de uma humanização sustentável da Medicina. RBM. Revista Brasileira de Medicina, 68, $12-4$. 
Brasil (2001). Conselho Nacional de Educação. Câmara de Educação Superior. Resolução CNE/CES N4, de 7 de novembro de 2001. http://portal.mec.gov.br/cne/arquivos/pdf/CES04.pdf.

Brasil (2019). Conselho Federal de Medicina. Resolução nº 2.217, de 27 de setembro de 2019. Código de Ética Médica. http://www.in.gov.br/materia//asset_publisher/Kujrw0TZC2Mb/content/id/48226289/do1-2018-11-01-resolucao-n-2-217- de-27-de-setembro-de-2018-48226042

Brasil (2014), Ministério da Educação. Conselho Nacional de Educação. Câmara de Educação Superior. Resolução Nº̂, de 13 de janeiro de 2014.

http://portal.mec.gov.br/index.php?option=com_docman\&view=download\&alias=14957-rces001-14\&category_slug=janeiro-2014-pdf\&Itemid=30192.

Brasil (2012). Ministério da Saúde. Conselho Nacional de Saúde. Carta dos direitos dos usuários da Saúde. Brasília: Ministério da Saúde.

Brasil (1990). Ministério da Saúde. Lei Orgânica da Saúde no 8.080, de 19 de setembro de 1990. Lei Orgânica da Saúde. Dispõe sobre as condições para a promoção, proteção e recuperação da saúde, a organização e o funcionamento dos serviços correspondentes e dá outras providências. http://www.planalto.gov.br/ccivil_03/leis/18080.htm

Brasil (2004). Ministério da Saúde. HumanizaSUS: Política Nacional de Humanização: a humanização como eixo norteador das práticas de atenção e gestão em todas as instâncias do SUS. Brasília, Distrito Federal

Braz, F. D. A. F. (2013). A importância do acolhimento aos usuários da atenção básica: uma assistência humanizada.

Camargo, A., Almeida, M. A. S. D., \& Morita, I. (2014). Ética e bioética: o que os alunos do sexto ano médico têm a dizer. Revista Brasileira de Educação Médica, 38, 182-189.

Casate, J. C., \& Corrêa, A. K. (2012). A humanização do cuidado na formação dos profissionais de saúde nos cursos de graduação. Revista da Escola de Enfermagem da USP, 46, 219-226.

Cavalcante, T. M., de Melo, B. T., de Luna Batista, R. S., Jordão, D. A., Beserra, K. S., de Andrade, L. S. G., ... \& Bomfim, A. M. A. (2017). Uma experiência de integração ensino, serviço e comunidade de alunos do curso de graduação em medicina na atenção básica no município de Maceió. Revista Ciência Plural, $3(3), 69-80$.

da Silva Chaves, F., \& dos Santos, F. D. A. S. (2017). A espiritualidade e a medicina integrativa no contexto da saúde integral do ser humano. Estudos teológicos, $57(2), 382-400$

Daltro, M. R., \& Bueno, G. (2010). Ludicidade e narrativa: estratégias de humanização na graduação médica. Revista Brasileira de Educação Médica, 34, 497505 .

DeCS (2017). Descritores em Ciências da Saúde: consulta ao DeCS. http://decs.bvs.br/.

De Benedetto, M. A. C., Blasco, P. G., \& Gallian, D. M. C. (2013). Narrativas de estudantes de medicina e enfermagem: o que elas nos revelam. Revista Brasileira de Medicina, São Paulo, 70, 11-17.

de Oliveira, M. F. R., Castanho, J. L. C., \& Oliveira, R. S. C. (2019). Saúde e marginalização social: suprimindo falhas curriculares. Revista Brasileira De Medicina De Família E Comunidade, 14(41), 1793-1793.

Ferreira, D. C., Souza, I. D., Assis, C. R. S., \& Ribeiro, M. S. (2014). A experiência do adoecer: uma discussão sobre saúde, doença e valores. Revista Brasileira de Educação Médica, 38, 283-288.

Ferreira, T. T., Borges, M. D. F., Zanetti, G. C., Lemos, G. L., Gotti, E. S., Tomé, J. M., ... \& Rezende, E. A. M. R. D. (2018). Percepção de acadêmicos de medicina e de outras áreas da saúde e humanas (ligadas à saúde) sobre as relações entre espiritualidade, religiosidade e saúde. Revista Brasileira de Educação Médica, 42, 67-74.

Floss, M., Porto, B. D. L., Dall'Agnol, A. F., Costa, M. M. G. D., \& Susin, L. R. O. (2013). A humanização através do programa Recrutas da Alegria da FURG: um relato de experiência. Revista Brasileira de Educação Médica, 37, 464-470.

Ganong, L. H. (1987). Integrative reviews of nursing research. Research in nursing \& health, 10(1), 1-11.

Garcia, J. A. P. D. M., Rampim, D. B., Schor, P., \& Silva, J. F. R. D. (2010). Avaliação da disciplina observação da prática médica pelos graduandos de medicina da Unifesp-Escola Paulista de Medicina. Revista Brasileira de Educação Médica, 34(4), 542-548.

Garcia, M. A. A., Ferreira, F. P., \& Ferronato, F. A. (2012). Experiências de humanização por estudantes de medicina. Trabalho, Educação e Saúde, 10, 87-106. Gonzalez, R. F., \& Rodrigues, B. (2012). Reflexões sobre o processo ensino-aprendizagem da relação médico-paciente. Revista Bioética, 20(2), $244-254$.

Gouveia, Á. R. D. S., Lima, D. P. A. D., Ribeiro, L. S., Costa, R. F. B. D., Bezerra, K. F. D. O., \& Deininger, L. D. S. C. (2017). Vivências de uma acadêmica de medicina em estágio realizado em uma comunidade rural. Rev. enferm. UFPE on line, 2217-2226.

Hotimsky, S. N., \& Schraiber, L. B. (2005). Humanização no contexto da formação em obstetrícia. Ciência \& Saúde Coletiva, $10,639-649$.

Kipper, D. J., \& Loch, J. A. (2009). Questionamentos éticos relativos à graduação e à residência médica. Revista Bioética, 10(2).

Kreischer, E. D., Alonso, P. D. A. P., Salles, P. D. M., \& Ramos, R. D. S. (1996). Os direitos do paciente segundo o posicionamento de médicos e enfermeiros: pesquisa exploratória. Revista Brasileira de Enfermagem, 49, 625-638. 
Maeyama, M. A., Cutolo, L. R. A., Chaves, M. V., \& Barni, R. D. S. (2018). Projeto Sérgio Arouca: relato de experiência. Revista Brasileira de Educação Médica, 42, 47-56.

Marco, M. A. D., Degiovani, M. V., Torossian, M. S., Wechsler, R., Joppert, S. M. H., \& Lucchese, A. C. (2013). Comunicação, humanidades e humanização: a educação técnica, ética, estética e emocional do estudante e do profissional de saúde. Interface-Comunicação, Saúde, Educação, $17,683-693$.

Martins, A. D. F., \& Bellodi, P. L. (2016). Mentoring: uma vivência de humanização e desenvolvimento no curso médico. Interface-Comunicação, Saúde, Educação, 20, 715-726.

Mônaco, C. (2010). SOBRAMFA 18 anos-sonhos, perseverança e entusiasmo na Educação Médica. Mundo saúde (1995), 347-356.

Nehmy, R. M. Q., Mota, J. A. C., Gonçalves, A. J. P., Gontijo, N. P., \& Guimarães, Y. L. (2009). Uma experiência de extensão, iniciação científica e de formação humanista de estudantes de medicina: o projeto Abraçarte. Rev. Méd. Minas Gerais, 19(4 supl 2), 64-70.

Nilson, L. G., Maeyama, M. A., Kaminagakura, F. G., de Souza, T. C., \& Dolny, L. L. (2018). Acolhimento na percepção de estudantes de medicina. Revista de APS, 21(1).

Nogueira, A. P. F., Lucena, K. D. T. D., Pinto, B. P. V., Araújo, M. F., Ataíde, M. C. C. D., Pedrosa Neto, W. D., \& Deininger, L. D. S. C. (2017). A importância do uso do genograma para compreensão da dinâmica familiar. Rev. enferm. UFPE on line, 5110-5115.

Silveira, R. C. D. C. P., \& Galvão, C. M. (2005). O cuidado de enfermagem e o cateter de Hickman: a busca de evidências. Acta Paulista de enfermagem, 18, 276-284.

Oliveira, I. F. D., Peluso, B. H. B., Freitas, F. A., \& Nascimento, M. C. D. (2017). Homeopatia na graduação médica: trajetória da Universidade Federal Fluminense. Revista Brasileira de Educação Médica, 41, 240-250.

Pereira, A. T., Gallian, D. M. C., Reginato, V., \& De Benedetto, M. A. C. (2016). Percepção de alunos de medicina com a dramatização: uma experiência pedagógica. Revista Brasileira de Educação Médica, 40, 497-505.

Pinheiro, T. R. S. P., Benedetto, M. D., \& Blasco, P. G. (2011). Ambulatório Didático de Cuidados Paliativos: aprendendo com os nossos pacientes. Revista Brasileira de Medicina, 68(1), 19-25.

Poles, T. P. G., Oliveira, R. A., Anjos, R. M. P., \& Almeida, F. A. (2018). Percepção dos internos e recém-egressos do curso de medicina da PUC-SP sobre sua formação para atuar na Atenção Primária à Saúde. Revista Brasileira de Educação Médica, 42, 121-128.

Rebello, M. T. M. P., \& Rodrigues Neto, J. F. (2012). A humanização da assistência ao parto na percepção de estudantes de medicina. Revista Brasileira de Educação Médica, 36, 188-197.

Ribeiro, J. R., \& Poles, K. (2019). Cuidados paliativos: prática dos médicos da estratégia saúde da família. Revista Brasileira de Educação Médica, 43, 62-72.

Rios, I. C. (2012). Comunicação em medicina. Revista de Medicina, 91(3), 159-162.

Rios, I. C. (2016). Humanidades médicas como campo de conhecimento em medicina. Revista Brasileira de Educação Médica, 40, $21-29$.

Rios, I. C. (2009). Humanização: a essência da ação técnica e ética nas práticas de saúde. Revista brasileira de educação médica, 33, $253-261$.

Rios, I. C., \& Sirino, C. B. (2015). A humanização no ensino de graduação em medicina: o olhar dos estudantes. Revista brasileira de educação médica, 39, 401-409.

Rosevics, L., Aguiar, D. A., Borges, C. R., Hasegawa Filho, R., Yamashita, T. S., Manchak, A. C., \& Azevedo, V. F. (2014). ProCura-a arte da vida: um projeto pela humanização na saúde. Revista Brasileira de Educação Médica, 38, 486-492.

Santos, M. R. C., Lins, L., \& Menezes, M. S. (2018). “As intermitências da morte” no ensino da ética e bioética. Revista Bioética, 26, 135-144.

Savaris, P. K., Reberte, A., Bortoluzzi, M. C., Schlemper Júnior, B., \& Bonamigo, É. L. (2013). Julgamento simulado como estratégia de ensino da ética médica. Revista Bioética, 21(1), 150-157.

Silva, I. D. D., \& Silveira, M. D. F. D. A. (2011). A humanização e a formação do profissional em fisioterapia. Ciência \& Saúde Coletiva, 16, 1535-1546.

Silva, M. R. D., Gallian, D. M. C., \& Schor, P. (2016). Literatura e humanização: uma experiência didática de educação humanística em saúde. Revista Brasileira de Educação Médica, 40, 93-101.

Silva, M. G. D., Marcelino, M. C., Rodrigues, L. S. P., Toro, R. C., \& Shimo, A. K. K. (2014). Violência obstétrica na visão de enfermeiras obstetras. 15(4), $720-728$.

Soares, M. O. M., Higa, E. D. F. R., Passos, A. H. R., Ikuno, M. R. M., Bonifácio, L. A., Mestieri, C. D. P., \& Ismael, R. K. (2014). Reflexões contemporâneas sobre anamnese na visão do estudante de medicina. Revista Brasileira de Educação Médica, 38, 314-322.

Sousa, M. S. A., Gallian, D. M., \& Maciel, R. M. (2012). Humanidades médicas no Reino Unido: uma tendência mundial em educação médica hoje. Revista de Medicina, 91(3), 163-173.

Takahagui, F. M., Moraes, É. N. D. S., Beraldi, G. H., Akamine, G. K., Basile, M. A., \& Scivoletto, S. (2014). MadAlegria-Estudantes de medicina atuando como doutores-palhaços: estratégia útil para humanização do ensino médico? Revista Brasileira de Educação Médica, 38, $120-126$. 
Research, Society and Development, v. 11, n. 1, e57711125337, 2022 (CC BY 4.0) | ISSN 2525-3409 | DOI: http://dx.doi.org/10.33448/rsd-v11i1.25337

Taquette, S. R., \& Minayo, M. C. D. S. (2015). Ensino-aprendizagem da metodologia de pesquisa qualitativa em medicina. Revista Brasileira de Educação Médica, 39, 60-67.

Zeni, P. (2011). Abordagem da humanização na formação acadêmica dos cursos da área da saúde.

Zeni, P., \& Cutolo, L. R. A. (2011). Abordagem da humanização na formação acadêmica dos cursos de graduação da área da saúde da UNOCHAPECÓAvaliação dos Planos Pedagógicos de Cursos [Approach of humanization in academic undergraduate courses in the area of health UNOCHAPECÓ]. Saúde \& Transformação Social/Health \& Social Change, 2(3), 88-95.

Zeni, P., \& Cutolo, L. R. A. (2014). Sentidos e dificuldades de práticas curriculares de humanização. Saúde \& Transformação Social/Health \& Social Change, $5(3), 63-74$ 